\title{
Gender-based differences in game-related statistics between winning and losing teams in an amateur handball league
}

\author{
Sveinn Porgeirsson ${ }^{1,2 \bowtie}$, Miguel Pic ${ }^{3}$, Demetrio Lozano ${ }^{4}$, Olafur Sigurgeirsson ${ }^{5}$, Damir Sekulic $^{2}$, and Jose M. Saavedra ${ }^{1}$ \\ ${ }^{1}$ Physical Activity, Physical Education, Sport and Health Research Centre, Sports Science Department, School of Science and Engineer- \\ ing, Reykjavik, Iceland; ' ${ }^{2}$ Faculty of Kinesiology, University of Split, Split, Croatia; ${ }^{3}$ Motor Action Research Group (GIAM), Institute of \\ Sport, Tourism, and Service, South Ural State University, Chelyabinsk, Russia; ${ }^{4}$ VALORA Research Group, Health Sciences Faculty, \\ Universidad San Jorge, Zaragoza, Spain; and ${ }^{5}$ HBStatz Company, Reykjavik, Iceland
}

\begin{abstract}
Background: The literature on performance analysis in team handball has increased at the top level, but there has been far less research published at the amateur level. Objective: The objectives of the present study were: (i) to compare handball game-related statistics by match result (winning and losing teams) for the men's and women's teams in an amateur league, (ii) to compare handball game-related statistics by gender, and (iii) to identify characteristics that discriminated performance in amateur men and women handball leagues. Methods: The game-related statistics of the 190 matches (113 men, 77 women) played in the 2018/19 Icelandic League by 12 men and 8 women teams were analysed. Their intra- and inter-observer internal consistency and reliability were at levels considered to be good or very good for the games of both genders. Differences in the game statistics between match outcomes (winning or losing teams for each gender) and between the genders were determined using the unpaired $t$-test or Mann-Whitney $U$ test, and the corresponding effect sizes were calculated. Results: Large differences between the winning and losing teams were shown by shots, goalkeeper blocked shots, and $9 \mathrm{~m}$ shots for men, and by shots, goalkeeper blocked shots and $7 \mathrm{~m}$ shots for women. In the comparison between the genders, there were four variables that showed a moderate effect size (Cohen's $d>0.50$ ). A discriminant analysis applying the sample-splitting method was performed for each gender to determine the game statistics that best characterized the match outcomes. The resulting predictive models correctly classified $84 \%$ of the matches using five variables for men and $87 \%$ of the matches using two variables for women. Conclusions: The results could be used to better understand the structure of the game in amateur leagues, and to improve the performance of teams.
\end{abstract}

Keywords: performance analysis, notational analysis, shots

\section{Introduction}

Team-handball (handball) developed from an 11-a-side outdoor sport at the beginning of the 20th century to a 7-a-side and more compact, full-body contact, indoor sport. Handball is played worldwide at different competition levels by both genders and has been a fixture in the Olympics since 1972 for men and 1976 for women. The main objective is to score in the opponent's goal by outplaying the defence and throwing the ball past the goalkeeper. The modern game is fast and intermittent, and there are frequent transitions between offence and defence actions during the official $2 \times 30$ minutes playing time (Büchel et al., 2019). It is a dynamic sport with physical, physiologi$\mathrm{cal}$, and technical demands on the player as an individual, and various cognitive, tactical, and social challenges for the whole team as a unit (Wagner et al., 2014). Since the beginning of the millennium, the sport has implemented rule changes aimed at making the game faster and more spectacular to watch (Haugen \& Guvåg, 2018). For example, an influential change to the speed of play was the implementation of the rapid restart after a goal has been conceded. This allows the goal-conceding team to transition rapidly into a fast-break situation.

Nowadays, players rely primarily on aerobic metabolism, although the sport is characterized by anaerobic actions such as throwing, direction changes, jumping, and one-on-one situations at either end of the court (Póvoas et al., 2012). However, there are some factors in gameplay that differ between men and women: (i) women players cover a greater distance and play at a higher relative workload than men who play with more high-intensity actions such as tackles and direction changes (Michalsik \& Aagaard, 2015); (ii) throwing speed, since men players are generally taller and heavier, they throw harder although, when this was analysed relative to fat-free mass, there were no differences observed between the genders in throwing speed (van den Tillaar \& Ettema, 2004); (iii) men handball players were found to have better jumping ability, acceleration, and change of directions than women players (Pereira et al., 2018).

$\triangle$ Corresponding author: Sveinn Porgeirsson, e-mail sveinntho@ru.is, ORCID ${ }^{\circledR}$ record https://orcid.org/0000-0001-5047-7147

Article history: Received April 15 2021, Accepted January 3 2022, Published January 192022

Copyright: @ 2021 The Author(s). Published by Palacký University Olomouc. This is an open access article distributed under the terms of the Creative Commons Attribution License (https://creativecommons.org/licenses/by/4.0/), which permits unrestricted use, distribution, and reproduction in any medium, provided the original author and source are credited. This license does not cover any third-party material that may appear with permission in the article. 
Research on handball has increased over the last few years, especially in physical, physiological, injury, and performance-related topics (Saavedra, 2018). Results in sports competitions depend on a varied number of factors that have a complex inter-relationship. Performance analysis in the form of notational analysis is one of the tools available to provide sports scientists and coaches with objective information on which to ground decisions before, during, and after competition (Lord, 2020). It should highlight a team's key performance parameters to assist the coach in their work of developing the team (Wright et al., 2013).

One part of performance analysis is the analysis of game-related statistics through official statistics or observational studies. At the international level (Meletakos et al., 2020), such statistics offer better insight into how teams achieve success. Regarding the men's game, a recent publication on World Championship level games (Almeida et al., 2020) found that efficiency in wing and 9 $\mathrm{m}$ shots together with more blocked shots in defence characterized the top eight teams as against the less successful teams. Another study on the men's World Championships between 2005 and 2019 (Meletakos et al., 2020) found breakthrough efficiency, the goalkeeper saved shots, $6 \mathrm{~m}$ efficiency, and the number of steals made by the defence discriminated the top four teams from the others. Other research has studied the conventional role of the goalkeeper (Gutiérrez-Aguilar et al., 2016; Hatzimanouil, 2020) and the effect of rule changes on the substitution of the goalkeeper for an extra offensive player observed from the notational analysis of game-related statistics (Gümüş \& Gençoğlu, 2020).

Regarding the women's game, the performance indicators appear to be different from the men's, with less dependence on players' height and weight and greater dependence on expertise variables such as age, international experience, and goals scored combined with World Championship game-related statistics of shots, goals, and team scoring efficiency (Costa et al., 2017). Performance analysis of offensive actions in women's World Championships spanning 2007-2017 (de Paula et al., 2020) has underscored the different profiles of backcourt players whose shots at goal attempts are more predictable than those of pivots and wings who show less efficiency in this aspect. Other conclusions of that study were that, in balanced matches, the particular variables contributing importantly to the final game outcome were blocked throws, goalkeeper efficiency, and steals in defence, together with attack efficiency and technical fouls, this latter negatively affecting the overall chances of winning (de Paula et al., 2020).

Previous research on handball performance has been focused on top international levels or professional leagues. There is therefore a gap in knowledge about which are the discriminating factors at the domestic level in a semi-professional or amateur league. For several decades now, amateur Icelandic handball has produced a number of professional players, some of whom play at a worldclass level and feature in the Champions League and have earned honours abroad. A study of this league could provide relevant information for scientists and coaches to apply in similar circumstances. Given this context, the objectives of the present study were: (i) to compare handball game-related statistics by match result (winning and losing teams) for the men's and women's teams in an amateur league, (ii) to compare handball game-related statistics by gender, and (iii) to identify characteristics that discriminated performance in amateur men and women handball leagues.

\section{Methods}

\section{Participants}

The outcomes and game-related statistics of 190 matches (113 men, 77 women) played in the 2018/19 amateur Icelandic top League for both genders were analysed. In Iceland, men compete in a 12-team top league with three league levels in total and women compete in an 8-team league. The players making up the teams are mostly adults (over 18 years old), but it was the decision of each coach to include younger players in the team. Archival data were obtained from the manager of HBStatz statistics company. This company provided game-related statistics to the Icelandic national handball federation and put a summary of these game-related statistics up on their official website. Twenty-six tied matches were excluded from the analysis because of the outcome.

\section{Procedures}

The data were originally entered by a trained observer on a computer/tablet into an online database on a custom-designed website platform. They were subsequently extracted and entered into an Excel spreadsheet by a technician, a random check by one of the authors (SP) in order to detect possible errors, followed by their statistical analysis. No informed consent was necessary as the information used is in the public domain on the website (men league: https://hbstatz.is/OlisDeildKarlaLeikir2018.php, women league: https://hbstatz.is/OlisDeildKvennaLeikir2018.php). The analysis of public data taken from websites is common in the field of handball (Calin, 2010; Meletakos et al., 2011; Pollard \& Gómez, 2012; Yamada et al., 2011). The dependent variable in the study is match outcome (winning/losing teams for the men and women leagues), and the independent variables are the game-related statistics listed in Table 1.

An observational method was used to validate the study data (Anguera, 2003; Anguera et al., 2017), and an ad hoc instrument was designed to observe and register data using the LINCE software package (Gabín et al., 2012). The variables were organized into four subgroups according to the nature of the actions registered: (i) shots (shots, $6 \mathrm{~m}$ shots, $7 \mathrm{~m}$ shots, $9 \mathrm{~m}$ shots, wing shots, fast-break shots, breakthrough shots); (ii) cards and exclusions (yellow cards, red cards, 2-min exclusions); (iii) goalkeeper-blocked shots (GB $6 \mathrm{~m}$ shots, GB $7 \mathrm{~m}$ shots, GB $9 \mathrm{~m}$ shots, GB wing shots, GB fast-break shots, and GB breakthrough shots); and (iv) other variables (assists, technical fouls, steals). Cronbach's alpha $(\alpha)$ was used to determine internal consistency, and 
the intra-class correlation coefficients (ICC) and Cohen's kappa (к) values to determine reliability. Two randomly chosen matches for each gender were analysed, calculating the intra-observer internal consistency and reliability (at two different times) and inter-observer internal consistency and reliability. The observation record was compared with the record downloaded from the official website, resulting in the website data being used in the final analysis. The internal consistency and the reliability thresholds, between 0 and 1 (Peterson $\&$ Kim, 2013), were set at: for $\alpha$ (internal consistency), < .50 unacceptable, .51-.60 poor, $.61-.70$ questionable, .71-.80 acceptable, .81-.90 good, and $\geq .91$ excellent (George \& Mallery, 2003); for ICC (reliability), $\leq .50$ poor, .51-.75 moderate, .76-.90 good, and $\geq .91$ excellent (Koo \& Li, 2016); and for $\kappa$ (reliability) $<.01$ no agreement, .01-.20 poor, .21-.40 discrete/ regular, .41-.60 moderate, .61-.80 good, and .81-1.00 very good (Landis $\&$ Koch, 1977). Table 2 lists the internal consistency and reliability of the intra-observer and inter-observer means. Both can be considered to be good or very good for both men and women.

\section{Statistical analysis}

Basic statistical descriptors (mean and standard deviation) were calculated for each game-related statistic by match outcome (winning and losing teams) and by gender. The normality of each variable was determined using the Kolmogorov-Smirnov test. For the differences between winning/losing teams and men/women, a parametric (unpaired $t$-test) or non-parametric (Mann-Whitney $U$ test) test was applied depending on whether or not the variable met normality, respectively. The effect sizes of the differences were calculated and interpreted following literature recommendations (Cohen, 1988): > 0.2 small, > 0.5 moderate, $>0.8$ large. A discriminant analysis was performed separately for men and women using the sample-splitting method depending on match outcome (winning and losing teams). The criterion used to determine whether or not a

Table 1 Definitions of the game-related statistics

\begin{tabular}{|c|c|}
\hline Variable & Definition \\
\hline Shots & Percentage of converted shots relative to the number of shots made. \\
\hline $6 \mathrm{~m}$ shots & $\begin{array}{l}\text { Percentage of converted shots at } 6 \mathrm{~m} \text { relative to the number of shots made. The shot is from a zone outside the } 45^{\circ} \text { angle from the left and } \\
\text { the right. }\end{array}$ \\
\hline $7 \mathrm{~m}$ shots & Percentage of penalties $(7 \mathrm{~m})$ converted relative to the number of penalties taken. \\
\hline $9 \mathrm{~m}$ shots & $\begin{array}{l}\text { Percentage of converted shots at } 9 \mathrm{~m} \text { relative to the number of shots made. The shot is from a backcourt player either (a) over or through the } \\
\text { defence, or (b) after a breakthrough but with a defence player in front. }\end{array}$ \\
\hline Wing shots & $\begin{array}{l}\text { Percentage of converted shots from the wing area relative to the number of shots made. The shot is from a zone within the } 45^{\circ} \text { angle from the } \\
\text { left and the right without a defence player in front. }\end{array}$ \\
\hline Fast-break shots & $\begin{array}{l}\text { Percentage of shots converted in a fast-break situation (rapid switch from defence to attack without the defence organized) relative to the } \\
\text { number of shots made in this situation. }\end{array}$ \\
\hline Breakthrough shots & $\begin{array}{l}\text { Percentage of shots converted in a breakthrough situation relative to the number of shots made in this situation (a) from a backcourt player } \\
\text { after breakthrough in the } 9 \mathrm{~m} \text { zone without a defence player in front, (b) from the pivot after a 1:1 situation, (c) from the left or right back } \\
\text { after a breakthrough of a 1:1 situation. }\end{array}$ \\
\hline Yellow cards & Yellow cards received by each player and/or coaching staff member. \\
\hline Red cards & Red cards received by each player and/or coaching staff member. \\
\hline 2-min exclusions & 2-minute suspension received by each player and/or coaching staff member. \\
\hline Assists & Number of passes from one offensive player to another leading directly to a goal scored. \\
\hline Technical fouls & Number of turnovers made by the offensive team where the ball is awarded to the defence due to a foul in offence. \\
\hline Steals & Number of turnovers in favour of the defence due to actions of anticipation and snatching the ball. \\
\hline GB shots & Percentage of shots stopped relative to the number of shots made by the attackers. \\
\hline GB 6 m shots & Percentage of $6 \mathrm{~m}$ shots stopped relative to the number of shots made by the attackers. \\
\hline GB 7 m shots & Percentage of penalties $(7 \mathrm{~m})$ stopped relative to the number of penalties taken by the attackers. \\
\hline GB 9 m shots & Percentage of $9 \mathrm{~m}$ shots stopped relative to the number of shots made by the attackers. \\
\hline GB wing shots & Percentage of shots stopped in the wing area relative to the number of shots made by the attackers. \\
\hline GB fast-break shots & Percentage of shots stopped in fast-break situations relative to the number of shots made by the attackers. \\
\hline GB breakthrough shots & Percentage of shots stopped in breakthrough situations relative to the number of shots made by the attackers. \\
\hline
\end{tabular}

Note. GB = goalkeeper-blocked.

Table 2 Intra- and inter-observer internal consistency (Cronbach's alpha $-\alpha$ ) and reliability (intra-class correlation coefficient - ICC and Cohen's kappa $-\kappa$ )

\begin{tabular}{|c|c|c|c|c|c|c|c|c|c|c|c|c|}
\hline \multirow[b]{3}{*}{ Variable group } & \multicolumn{6}{|c|}{ Men } & \multicolumn{6}{|c|}{ Women } \\
\hline & \multicolumn{3}{|c|}{ Intra-observer } & \multicolumn{3}{|c|}{ Inter-observer } & \multicolumn{3}{|c|}{ Intra-observer } & \multicolumn{3}{|c|}{ Inter-observer } \\
\hline & $\alpha$ & ICC & $\kappa$ & $\alpha$ & ICC & $\kappa$ & $\alpha$ & ICC & $\kappa$ & $\alpha$ & ICC & $\kappa$ \\
\hline Shots & 1.000 & 1.000 & 1.000 & 1.000 & 1.000 & 1.000 & 1.000 & 1.000 & 1.000 & 1.000 & 1.000 & 1.000 \\
\hline Cards and exclusions & 1.000 & 1.000 & 1.000 & 1.000 & 1.000 & 1.000 & 1.000 & 1.000 & 1.000 & 1.000 & 1.000 & 1.000 \\
\hline Goalkeeper-blocked & 1.000 & 1.000 & 1.000 & .937 & .937 & .880 & .917 & .917 & .843 & .790 & .790 & .641 \\
\hline Other variables & .797 & .797 & .658 & .795 & .795 & .653 & .883 & .883 & .785 & .783 & .783 & .621 \\
\hline Mean & .949 & .949 & .915 & .933 & .933 & .883 & .950 & .950 & .907 & .893 & .893 & .816 \\
\hline
\end{tabular}


variable is discriminatory was Wilks's lambda $(\lambda)$, which measures the deviations within each group relative to the total deviations. The sample-splitting method initially included the variable that best minimized the value of $\lambda$ under the provision that the value of $F$ was greater than a certain critical value $(F=3.84$, "include"). From that point on, the method combined the variables pairwise. The new variable was selected if $\lambda$ was greater than the value of the input $F$. However, before introducing a variable, we attempted to eliminate some of those that had already been selected, as long as the increase in the minimized $\lambda$ was below a critical threshold ( $F=2.71$, "remove"). We thus calculated $\lambda$, the canonical correlation index (deviations of the between-group discriminant scores relative to the total deviations), and the percentage of correctly classified matches (winning and losing teams). A $p$-value $<.05$ was considered to be statistically significant. The statistical analysis was performed with the software package IBM SPSS Statistics (Version 25.0; IBM, Armonk, NY, USA).

\section{Results}

Table 3 presents the basic descriptors of the variables by match outcome (win/lose) for the men's teams. Three variables showed a large effect size $(d>0.80)$ or close in differentiating between winning and losing teams. In order of decreasing value of effect size, these variables were: shots $(d=1.18)$, GB shots $(d=0.93)$, and $9 \mathrm{~m}$ shots $(d=0.73)$.

Table 4 presents the basic descriptors of the variables by match outcome (winning/losing teams) for the women's teams. Five variables showed a large effect size $(d>0.80)$ or close in differentiating between winning and losing teams. In order of decreasing value of effect size, these variables were: Shots $(d=1.38)$, GB shots $(d=1.27), 7 \mathrm{~m}$ shots $(d=1.00)$, GB $9 \mathrm{~m}$ shots $(d=0.93)$, and assists $(d=0.78)$.

Table 5 presents the basic descriptors of the variables by gender (men/women). Four variables showed a moderate effect size $(d>0.5)$ in differentiating between winning and losing teams. In order of decreasing value of effect size, these variables were: technical fouls $(d=-0.78), 2$-minutes exclusion $(d=0.74)$ red cards $(d=0.61)$ and, $9 \mathrm{~m}$ shots $(d=0.51)$.

Table 6 presents the results of the discriminant analysis (Wilks's lambda, the canonical correlation index, and the percentage of teams correctly classified) for the match outcome by gender. The men's predictive model correctly classified $84 \%$ of matches using five variables: shots, GB shots, steals, technical fouls, and GB 7 m shots. The women's predictive model correctly classified $87 \%$ of matches using two variables: GB shots and shots.

\section{Discussion}

The present study analysed 190 matches played during one season of an amateur handball league. There have been previous analyses of game-related statistics at the top level for European Championships (2002-2010; Skarbalius et al., 2013) and World Championships (2003, Hassan, 2014; 2005-2009, Meletakos et al., 2011) and a combination of different championships (2004-2010; Bilge, 2012). To the best of our knowledge, this is the first study to report the state of game-related statistics in an amateur handball league. Four variables differentiated between winning and losing teams for men (shots, GB shots, $9 \mathrm{~m}$ shots, and GB $9 \mathrm{~m}$ shots) and seven for women (shots, GB shots, 7 $\mathrm{m}$ shots, GB $9 \mathrm{~m}$ shots, assists, red cards, breakthrough shots), but when the two genders were compared there

Table 3 Basic descriptors (mean and standard deviation), unpaired-sample $t$-test (parametric test), Mann-Whitney $U$ test (non-parametric test), $p$-value, and the effect size of the differences (Cohen's $d$ ) for each variable according to the match outcome in men

\begin{tabular}{|c|c|c|c|c|c|c|}
\hline Variable & Winners & Losers & $t$ & $u$ & $p$ & Cohen's $d$ \\
\hline Shots $(\%)^{a}$ & $62.05 \pm 7.32$ & $53.99 \pm 7.56$ & 8.141 & & $<.001$ & 1.08 \\
\hline $6 \mathrm{~m}$ shots $(\%)^{a}$ & $70.72 \pm 20.64$ & $71.50 \pm 22.18$ & & 5934.5 & .723 & 0.04 \\
\hline $7 \mathrm{~m}$ shots $(\%)^{\mathrm{a}}$ & $71.40 \pm 29.47$ & $69.78 \pm 32.65$ & & 6368.0 & .972 & 0.05 \\
\hline $9 \mathrm{~m}$ shots $(\%)^{\mathrm{a}}$ & $50.17 \pm 12.89$ & $41.22 \pm 11.62$ & 5.486 & & $<.001$ & 0.73 \\
\hline Wing shots $(\%)^{\mathrm{a}}$ & $59.44 \pm 22.01$ & $55.85 \pm 21.00$ & & 5900.5 & .043 & 0.16 \\
\hline Fast-break shots $(\%)^{\mathrm{a}}$ & $74.88 \pm 26.47$ & $67.39 \pm 32.77$ & & 5659.5 & .130 & 0.25 \\
\hline Breakthrough shots $(\%)^{\mathrm{a}}$ & $78.68 \pm 19.92$ & $68.46 \pm 25.86$ & & 4577.0 & .004 & 0.45 \\
\hline Yellow cards ( $n)$ & $0.81 \pm 0.63$ & $0.95 \pm 0.65$ & & 5647.0 & .070 & 0.22 \\
\hline Red cards $(n)$ & $0.28 \pm 0.53$ & $0.25 \pm 0.52$ & & 6126.0 & .470 & 0.06 \\
\hline 2-min exclusions ( $n$ ) & $3.86 \pm 1.81$ & $3.58 \pm 1.86$ & & 5878.5 & .296 & 0.15 \\
\hline Assists (n) & $10.57 \pm 3.93$ & $8.90 \pm 3.15$ & & 4631.5 & $<.001$ & 0.47 \\
\hline Technical fouls $(n)$ & $8.19 \pm 3.54$ & $8.98 \pm 3.45$ & & 5442.5 & .003 & 0.23 \\
\hline Steals $(n)$ & $3.70 \pm 2.56$ & $2.95 \pm 1.90$ & & 5385.0 & .040 & 0.33 \\
\hline GB shots $(\%)^{b}$ & $34.66 \pm 7.94$ & $27.64 \pm 7.16$ & 6.962 & & $<.001$ & 0.93 \\
\hline GB $6 \mathrm{~m}$ shots $(\%)^{\mathrm{b}}$ & $24.18 \pm 22.26$ & $21.18 \pm 19.49$ & 1.056 & & .292 & 0.14 \\
\hline GB $7 \mathrm{~m}$ shots $(\%)^{\mathrm{b}}$ & $23.70 \pm 30.95$ & $18.20 \pm 21.43$ & & 5583.0 & .569 & 0.21 \\
\hline GB 9 m shots $(\%)^{b}$ & $44.39 \pm 13.81$ & $37.20 \pm 14.49$ & 3.818 & & $<.001$ & 0.51 \\
\hline GB wing shot $(\%)^{b}$ & $35.99 \pm 19.83$ & $31.99 \pm 22.30$ & & 5342.0 & .023 & 0.19 \\
\hline GB fast break $(\%)^{b}$ & $19.44 \pm 25.37$ & $13.46 \pm 20.40$ & & 4908.5 & .104 & 0.26 \\
\hline GB breakthroughs $(\%)^{\mathrm{b}}$ & $25.31 \pm 2.44$ & $17.98 \pm 1.72$ & & 4600.5 & .005 & 0.47 \\
\hline
\end{tabular}

Note. $\mathrm{GB}=$ goalkeeper-blocked. ${ }^{\mathrm{a}}$ number of shots converted/number of shots; ${ }^{\mathrm{b}}$ number of shots saved/number of shots. 
Table 4 Basic descriptors (mean and standard deviation), unpaired-sample $t$-test (parametric test), Mann-Whitney $U$ test (non-parametric test), $p$-value, and the effect size of the differences (Cohen's $d$ ) for each variable according to the match outcome in women

\begin{tabular}{|c|c|c|c|c|c|c|}
\hline Variable & Winners & Losers & $t$ & $U$ & $p$ & Cohen's d \\
\hline Shots $(\%)^{a}$ & $59.45 \pm 7.97$ & $48.12 \pm 8.47$ & 8.550 & & $<.001$ & 1.38 \\
\hline $6 \mathrm{~m}$ shots $(\%)^{\mathrm{a}}$ & $77.47 \pm 19.75$ & $71.50 \pm 22.18$ & & 2847.5 & .878 & 0.28 \\
\hline $7 \mathrm{~m}$ shots $(\%)^{\mathrm{a}}$ & $82.07 \pm 25.99$ & $69.78 \pm 32.65$ & & 2286.5 & .010 & 1.00 \\
\hline $9 \mathrm{~m}$ shots $(\%)^{\mathrm{a}}$ & $43.35 \pm 14.08$ & $41.22 \pm 11.61$ & 4.879 & & $<.001$ & 0.09 \\
\hline Wing shots $(\%)^{\mathrm{a}}$ & $55.08 \pm 22.82$ & $55.84 \pm 21.00$ & & 2539.0 & .123 & 0.03 \\
\hline Fast-break shots (\%) & $70.77 \pm 29.01$ & $67.40 \pm 32.77$ & & 2653.5 & .253 & 0.11 \\
\hline Breakthrough shots $(\%)^{a}$ & $80.82 \pm 18.50$ & $68.46 \pm 25.86$ & & 1975.5 & .023 & 0.55 \\
\hline Yellow cards $(n)$ & $0.69 \pm 0.57$ & $0.95 \pm 0.65$ & & 2962.0 & .992 & 0.11 \\
\hline Red cards $(n)$ & $0.01 \pm 0.01$ & $0.25 \pm 0.53$ & & 2810.5 & .043 & -0.64 \\
\hline 2-min exclusions $(n)$ & $2.56 \pm 1.43$ & $3.58 \pm 1.86$ & & 2697.5 & .324 & 0.61 \\
\hline Assists (n) & $11.69 \pm 3.97$ & $8.90 \pm 3.15$ & & 1386.5 & $<.001$ & 0.78 \\
\hline Technical fouls $(n)$ & $10.29 \pm 4.18$ & $8.98 \pm 3.45$ & 3.020 & & .003 & 0.34 \\
\hline Steals $(n)$ & $5.27 \pm 3.21$ & $2.95 \pm 1.90$ & & 2131.5 & .040 & 0.08 \\
\hline GB shots $(\%)^{b}$ & $37.72 \pm 8.62$ & $27.64 \pm 7.16$ & 8.126 & & $<.001$ & 1.27 \\
\hline GB 6 m shots $(\%)^{b}$ & $17.51 \pm 22.73$ & $21.18 \pm 19.49$ & & 2847.5 & .829 & 0.17 \\
\hline GB 7 m shots $(\%)^{b}$ & $17.34 \pm 22.23$ & $18.20 \pm 21.43$ & & 2028.5 & .010 & -0.04 \\
\hline GB 9 m shots $(\%)^{b}$ & $50.86 \pm 14.81$ & $37.19 \pm 14.49$ & 4.504 & & $<.001$ & 0.93 \\
\hline GB wing shot $(\%)^{\mathrm{b}}$ & $40.74 \pm 24.38$ & $31.99 \pm 22.30$ & 1.831 & & .069 & 0.37 \\
\hline GB fast break $(\%)^{\mathrm{b}}$ & $16.93 \pm 25.87$ & $13.48 \pm 20.40$ & & 2105.0 & .543 & 0.15 \\
\hline GB breakthroughs $(\%)^{b}$ & $21.79 \pm 22.99$ & $13.50 \pm 16.88$ & & 2975.5 & .043 & 0.41 \\
\hline
\end{tabular}

Note. $\mathrm{GB}=$ goalkeeper-blocked. ${ }^{\mathrm{a}}$ number of shots converted/number of shots; ${ }^{\mathrm{b}}$ number of shots saved/number of shots.

Table 5 Basic descriptors (mean and standard deviation), unpaired-sample $t$-test (parametric test), Mann-Whitney $U$ test (non-parametric test), $p$-value, and the effect sizes of the differences (Cohen's $d$ ) for each variable according to gender

\begin{tabular}{|c|c|c|c|c|c|c|}
\hline Variable & Men & Women & $t$ & $U$ & $p$ & Cohen's $d$ \\
\hline Shots $(\%)^{a}$ & $57.92 \pm 8.08$ & $53.96 \pm 9.98$ & 4.515 & & $<.001$ & 0.44 \\
\hline $6 \mathrm{~m}$ shots $(\%)^{\mathrm{a}}$ & $70.28 \pm 22.75$ & $76.47 \pm 22.55$ & & 15076.5 & .005 & 0.27 \\
\hline 7 m shots $(\%)^{a}$ & $71.20 \pm 20.50$ & $76.32 \pm 29.05$ & & 19785.5 & .050 & -0.26 \\
\hline 9 m shots $(\%)^{a}$ & $45.52 \pm 12.54$ & $38.78 \pm 13.94$ & 5.215 & & $<.001$ & 0.51 \\
\hline Wing shots $(\%)^{\mathrm{a}}$ & $57.67 \pm 21.53$ & $52.54 \pm 22.58$ & & 21126.0 & .007 & 0.23 \\
\hline Fast-break shots (\%) ${ }^{a}$ & $71.14 \pm 29.90$ & $67.19 \pm 34.11$ & & 21749.0 & .453 & 0.12 \\
\hline Breakthrough shots (\%) & $72.45 \pm 22.09$ & $75.13 \pm 22.20$ & & 18905.0 & .611 & -0.12 \\
\hline Yellow cards $(n)$ & $0.89 \pm 0.63$ & $0.70 \pm 0.61$ & & 18850.5 & .002 & 0.31 \\
\hline Red cards $(n)$ & $0.25 \pm 0.51$ & $0.02 \pm 0.15$ & & 17814.0 & $<.001$ & 0.61 \\
\hline 2-min exclusions $(n)$ & $3.67 \pm 1.83$ & $2.44 \pm 1.46$ & & 13575.5 & $<.001$ & 0.74 \\
\hline Assists $(n)$ & $9.67 \pm 3.51$ & $9.58 \pm 4.29$ & 1.244 & & .214 & 0.02 \\
\hline Technical fouls $(n)$ & $8.56 \pm 3.43$ & $11.72 \pm 4.55$ & -8.190 & & $<.001$ & -0.78 \\
\hline Steals $(n)$ & $3.40 \pm 2.27$ & $4.65 \pm 2.96$ & -4.220 & & $<.001$ & -0.48 \\
\hline GB shots $(\%)^{\mathrm{b}}$ & $31.13 \pm 8.15$ & $32.22 \pm 9.80$ & 0.220 & & .826 & 0.12 \\
\hline GB $6 \mathrm{~m}$ shots $(\%)^{\mathrm{b}}$ & $23.17 \pm 21.96$ & $16.27 \pm 20.03$ & & 17214.0 & .001 & 0.33 \\
\hline GB $7 \mathrm{~m}$ shots $(\%)^{\mathrm{b}}$ & $20.23 \pm 26.14$ & $13.51 \pm 20.53$ & & 17127.0 & .009 & 0.29 \\
\hline GB 9 m shots $(\%)^{\mathrm{b}}$ & $40.63 \pm 14.24$ & $44.75 \pm 16.32$ & -2.755 & & .006 & 0.27 \\
\hline GB wing shot $(\%)^{b}$ & $58.70 \pm 31.43$ & $51.16 \pm 32.66$ & -1.355 & & .428 & 0.24 \\
\hline GB fast break $(\%)^{\mathrm{b}}$ & $15.76 \pm 22.48$ & $16.19 \pm 22.70$ & & 17970.0 & .815 & 0.02 \\
\hline GB breakthroughs $(\%)^{\mathrm{b}}$ & $20.13 \pm 22.19$ & $18.43 \pm 21.70$ & & 18444.0 & .408 & 0.08 \\
\hline
\end{tabular}

Note. $\mathrm{GB}=$ goalkeeper-blocked. ${ }^{\mathrm{a}}$ number of shots converted/number of shots; ${ }^{\mathrm{b}}$ number of shots saved/number of shots.

Table 6 Discriminant analysis models by the match outcome (winning and losing teams) in men and women, giving the percentage correctly classified, Wilks's lambda, canonical correlation index, and variables included in the model by order of selection

\begin{tabular}{lcr}
\hline & Men & Women \\
\hline Percentage correctly classified & 84.1 & 87.0 \\
Wilks's lambda & .536 & .432 \\
Canonical correlation index & .681 & .794 \\
Variables selected & Shots, GB shots, steals, technical fouls, GB 7 m shots & GB shots, shots \\
\hline
\end{tabular}

Note. GB = goalkeeper-blocked. 
were only three variables they did not share as discriminating between winners and losers (technical fouls, red cards, $9 \mathrm{~m}$ shots). Finally, the predictive (discriminant analysis) models correctly classified as winning or losing $84 \%$ and $87 \%$ of the teams, using five and two variables for men and women respectively.

\section{Differences by match outcome (winning/losing teams)}

\section{for men}

For men, three variables showed differences between winning and losing teams with a large effect size $(d>0.8)$ or close, namely shots, GB shots and $9 \mathrm{~m}$ shots. The two variables that presented the greatest effect size were shots and GB shots This agrees with previous studies on the Champions League Final Four (Ferrari et al., 2014), World Cup (Hassan, 2014), and Olympic Games (Saavedra, Porgeirsson, Kristjánsdóttir, et al., 2018), and seems to suggest that relevant game-related statistics are similar in the amateur league and elite competitions. It is necessary to note that these variables (shots and GB shots) could be influenced by home advantage since home teams' effectiveness is better than that of away teams (Lago-Penas et al., 2013). Similarly, $9 \mathrm{~m}$ shots and GB $9 \mathrm{~m}$ shots differentiated between winning and losing teams. This also agrees with studies carried out on the Spanish professional league (Gómez et al., 2014), the Champions League Final Four (Ferrari et al., 2014), and Olympic Games (Saavedra, Porgeirsson, Kristjánsdóttir, et al., 2018). Since it is known that elite players achieve greater shooting speed (Gorostiaga et al., 2005) and efficiency (Massuça et al., 2014) than sub-elite players, it would seem that precision is more important than throwing speed. A recent study, for instance, found that handball players are able to reach high throwing speeds without losing accuracy (Vila \& Ferragut, 2019).

\section{Differences by match outcome (winning/losing teams) for women}

For women, five variables showed differences between winning and losing teams with a large effect size $(d>0.8)$ or close. Goalkeeper efficiency (GB shots) had been identified in previous research on elite players (de Paula et al., 2020) to be more important in balanced games, but assists to be more important in unbalanced games. This raises the question of the make-up of the present dataset in terms of unbalanced and balanced games, and of whether it is skewed in some way. Another two variables in the present study (assists and shots) differentiated between winning and losing teams, coherent with previous results indicating that shooting efficiency (Costa et al., 2017) and assists (Saavedra, Porgeirsson, Chang, et al., 2018) are important for the match outcome in the elite women game. The finding that $7 \mathrm{~m}$ shots also differentiated between winning and losing teams in this amateur league had not been observed at the World Championship level where this statistic was not a performance indicator (Ohnjec et al., 2008).

\section{Differences by gender}

Four variables showed differences between men and women teams with moderate effect sizes $(d>0.5): 9 \mathrm{~m}$ shot efficiency, red cards, 2-minutes exclusions and technical fouls. The $9 \mathrm{~m}$ shot efficiency was greater for men players, possibly due to their capacity for greater throwing speed (van den Tillaar \& Ettema, 2004), as also has been confirmed for Icelandic players in particular (Saavedra et al., 2019), despite the ball in the men's game being larger than in the women's. Independently, that more red cards are seen in the men matches might be explained by more high-intensity actions and tackles (Michalsik \& Aagaard, 2015) in which the defender is more often forced to make quick decisions, and is therefore pressured to make more mistakes in such duels. Finally, women matches present more technical fouls which are a combination of such offensive fouls as travelling, foot, charging, passive play, and double dribble. This is somewhat difficult to explain given the different nature of these game-action events. The limited data available and various other factors affecting play, e.g., style of defence and referees, could have influenced this result.

\section{Discriminatory power for men}

The discriminant analysis identified five variables (shots, GB shots, steals, technical fouls, GB 7 m shots) that correctly classify $84 \%$ of the men matches. The shots variable is a marker of how well the selection of opportunity and execution of each shot is made on offence. A recent study (Valentin, 2018) noted that shooting efficiency was greater for the top four teams in comparison to the other teams in the World Championships (24 teams) and European Championships (16 teams) from 1998-2016. Likewise, a study on the game-related statistics of the Olympics (2004-2016, Saavedra, Porgeirsson, Kristjánsdóttir, et al., 2018) found shots, GB shots, and technical fouls to be discriminatory for the winners, coherent with the present findings. Another study of recent World Championships (Meletakos et al., 2020) concluded that goalkeeper saved shots and steals discriminate the top four teams of the competitions from the lower seeded teams. The method used in that study's discriminant analysis was similar to that used here - winners were separated from losers for each particular game played during the season. Collectively, the results of this discriminant analysis of the Icelandic amateur league are in line with those for international championships. The exceptions are GB $7 \mathrm{~m}$ shots and steals, which seems to indicate that these variables are only predictive of performance in amateur leagues.

\section{Discriminatory power for women}

The discriminant analysis for the women matches identified just two variables (shots, GB shots) that correctly classify $87 \%$ of the winning and losing teams. These variables could be considered general indicators of performance. A previous study on handball in the Olympics (Saavedra, Porgeirsson, Chang, et al., 2018) found these same two variables but also technical fouls, steals, and GB fast-break shots to give $83 \%$ accuracy in distinguishing between 
winners and losers. A recent study of the World Championships between 2007 and 2017 (de Paula et al., 2020) found differences in match outcome discriminatory variables depending on how balanced the final result was, with three models being constructed; balanced (1-8 goal difference) with 8 variables; unbalanced (9-19 goal difference) with 7 variables; and very unbalanced ( $\geq 20$ goal difference) with 8 variables. All three models included goalkeeper efficiency and attack efficiency. A study of elite women handball players (Hatzimanouil, 2019) confirmed the importance of the goalkeeper's role. Results might indicate that amateur and elite level handball share this emphasis on the basics of offence (shots) and defence (GB shots) work (de Paula et al., 2020; Saavedra, Porgeirsson, Chang, et al., 2018). However, elite handball is more dynamic than the women's Icelandic amateur league as more variables discriminate between winners and losers.

\section{Limitations}

There were limitations to this study that need to be noted. Firstly, the perspective taken was static in that the gamerelated statistics were "the final result" without attention paid to what happened at each moment of the match (dynamic perspective; Prieto et al., 2015). Therefore the events logged provide only information about the result, not the process leading up to those events during an actual match. Secondly, the results reflect the handball played in an amateur men and women league in the 2018/19 season, and, as handball is developing rapidly, should be considered in this context for that specific skill level and point in time. Future research should aim to add more dimensions to the game-related statistics including links between variables, and to use data from different analyses such as physiological, psychological, and tactical variables.

\section{Conclusions}

In handball, it is common practice for the coach and staff to log important statistics during matches to inform their decisions made in team selection and tactics. For men, the present findings in the amateur league are in line with findings of other studies at the international level, and this might suggest that game-related statistics do not differ significantly between amateur and elite levels, while the dynamics of handball play behind the statistics remain less explored. So, three variables (shots, GB shots, $9 \mathrm{~m}$ shots) differentiating between winning and losing teams. Meanwhile, the discriminant analysis selected five variables to correctly classify $84 \%$ of the matches: shots, GB shots, steals, technical fouls, and GB $7 \mathrm{~m}$ shots. For women, the importance of a good tactical selection of shots to finalize an attack with high efficiency and good goalkeeping is highlighted at the amateur level. Five variables (shots, GB shots, $7 \mathrm{~m}$ shots, assists, and GB $9 \mathrm{~m}$ shots) differ between winning and losing teams. On the other hand, the discriminant analysis selected only two variables to correctly classify $87 \%$ of the matches (shots and GB shots). Our results suggest special attention should be awarded to the performance of the goalkeeper during matches for men and women.

\section{Conflict of interest}

The authors report no conflict of interest.

\section{References}

Almeida, A. G., Merlin, M., Pinto, A., Torres, R. S., \& Cunha, S. A. (2020). Performance-level indicators of men elite handball teams. International Journal of Performance Analysis in Sport, 20(1), 1-9. https://doi.org/10.1080/24748668.201 $\underline{9.1694305}$

Anguera, M. T. (2003). Observational methods (general). In R. Fernandez-Ballesteros (Ed.), Encyclopedia of psychological assessment (Vol. 2, pp. 632-637). Sage.

Anguera, M. T., Camerino, O., Castañer, M., Sánchez-Algarra, P., \& Onwuegbuzie, A. J. (2017). The specificity of observational studies in physical activity and sports sciences: Moving forward in mixed methods research and proposals for achieving quantitative and qualitative symmetry. Frontiers in Psychology, 8, Article 2196. https://doi.org/10.3389/fpsvg.2017.02196

Bilge, M. (2012). Game analysis of Olympic, World and European Championships in men's handball. Journal of Human Kinetics, 35(1), 109-118. https://doi. org/10.2478/v10078-012-0084-7

Büchel, D., Jakobsmeyer, R., Döring, M., Adams, M., Rückert, U., \& Baumeister, J. (2019). Effect of playing position and time on-court on activity profiles in German elite team handball. International Journal of Performance Analysis in Sport, 19(5), 832-844. https://doi.org/10.1080/24748668.2019.1663071

Calin, R. (2010). The analysis of the efficiency of using fast breaks in women handball during the World Championship in China, 2009. Science, Movement and Health, 2(Suppl.), 594-599. https://www.analefefs.ro/anale-fefs/2010/issue2-supplement/pe-autori/44.pdf

Cohen, J. (1988). Statistical power analysis for the behavioral sciences (2nd ed.). Lawrence Erlbaum Associates. https://doi.org/10.4324/9780203771587

Costa, G. D. C. T., Pedrosa, G. F., Souza, N. P., Gemente, F. R. F., Freire, A. B., \& Castro, H. O. (2017). Type of game practiced in handball according to the positions of the attackers: Analysis of the Women's World Handball Championship 2015. International Journal of Performance Analysis in Sport, 17(3), 360-373. https://doi.org/10.1080/24748668.2017.1345197

de Paula, L. V., Costa, F. E., Ferreira, R. M., Menezes, R. P., Werneck, F. Z., Coelho, E. F., \& Greco, P. J. (2020). Analysis of discriminatory game variables between winners and losers in women's handball world championships from 2007 to 2017. Kinesiology, 52(1), 54-63. https://doi.org/10.26582/k.52.1.6

Ferrari, W. R., dos Santos, J. V., \& Simoes Vaz, V. P. (2014). Offensive process analysis in handball: Identification of game actions that differentiate winning from losing teams. American Journal of Sports Sciences, 2(4), 92-96. https://doi. org/10.11648/j.ajss.20140204.14

Gabín, B., Camerino, O., Anguera, M. T., \& Castañer, M. (2012). Lince: Multiplatform sport analysis software. Procedia-Social and Behavioral Sciences, 46, 4692-4694. https://doi.org/10.1016/i.sbspro.2012.06.320

George, D., \& Mallery, P. (2003). SPSS for Windows step by step: A simple guide and reference (11.0 update) (4th ed.). Allyn \& Bacon.

Gómez, M. A., Lago-Peñas, C., Viaño, J., \& González-Garcia, I. (2014). Effect of game location, team quality and final outcome on game-related statistics in professional handball close games. Kinesiology, 46(2), 249-257. https://hrcak. srce.hr/file/194851

Gorostiaga, E. M., Granados, C., Ibañez, J., \& Izquierdo, M. (2005). Differences in physical fitness and throwing velocity between elite and amateur men handball players. International Journal of Sports Medicine, 26(5), 225-232. https:// doi.org/10.1055/s-2004-820974

Gümüş, H., \& Gençoğlu, C. (2020). The effects of the goalkeeper substitution rule as a new strategy in handball: Analysis of Men's European Handball Championship 2020. Acta Gymnica, 50(3), 113-121. https://doi.org/10.5507/ag.2020.015

Gutiérrez-Aguilar, Ó., Montoya-Fernández, M., Fernández-Romero, J. J., \& Saavedra-García, A. M. (2016). Analysis of time-out use in handball and its influence on the game performance. International Journal of Performance Analysis in Sport, 16(1), 1-11. https://doi.org/10.1080/24748668.2016.11868866

Hassan, A. (2014). Team handball World Cup Championship 2013 - Analysis study. Journal of Human Sport and Exercise, 9(Proc1), S409-S416. https://doi. org/10.14198/jhse.2014.9.Proc1.26

Hatzimanouil, D. (2019). Goalkeepers' rating, evaluation and classification, according to the number of games, participation time and effectiveness at the Women's European Handball Championship in 2018. International Journal of Performance and Analysis in Sport, 19(4), 595-607. https://doi.org/10.1080/2474 8668.2019.1642676

Hatzimanouil, D. (2020). Goalkeeper's efficiency in relation with throws from different attacking court areas in team handball. Journal of Physical Education and Sports Management, 7(1), 11-18. https://doi.org/10.15640/ipesm.v7n1a2

Haugen, K. K., \& Guvåg, B. (2018). Uncertainty of outcome and rule changes in European handball. European Journal of Sport Studies, 1(1). https://doi. org/10.12863/ejssax6x1-2018×2

Koo, T. K., \& Li, M. Y. (2016). A guideline of selecting and reporting intraclass correlation coefficients for reliability research. Journal of Chiropractic Medicine, 15(2), 155-163. https://doi.org/10.1016/i.jcm.2016.02.012

Lago-Penas, C., Gómez, M. A., Viaño, J., González-García, I., \& Fernández-Villarino, M. A. (2013). Home advantage in elite handball: The impact of the quality 
of opposition on team performance. International Journal of Performance Analysis in Sport, 13(3), 724-733. https://doi.org/10.1080/24748668.2013.11868684 Landis, J. R., \& Koch, G. G. (1977). The measurement of observer agreement for categorical data. Biometrics, 33(1), 159-174. https://doi.org/10.2307/2529310

Lord, F. (2020). Methods of performance analysis in team invasion sports: A systematic review. Journal of Sports Sciences, 38(20), 2338-2349. https://doi.org/0 $.1080 / 02640414.2020 .1785185$

Massuça, L., Honorio, S., \& Batista, M. (2014). Differences in individual proficiency of team-handball athletes from five performance groups. International Journal of Health, Physical Education and Computer Sciences in Sports, 15(1), 278-280.

Meletakos, P., Konstantinos, N., \& laoannis, B. (2020). Stable and changing characteristics of high-level handball as evidenced from World Men's Championships. Journal of Physical Education and Sport, 20(3), 1354-1361. https://doi. org/10.7752/ipes.2020.03187

Meletakos, P., Vagenas, G., \& Bayios, I. (2011). A multivariate assessment of offensive performance indicators in men's handball: Trends and differences in the World Championships. International Journal of Performance Analysis in Sport, 11(2), 284-294. https://doi.org/10.1080/24748668.2011.11868548

Michalsik, L. B., \& Aagaard, P. (2015). Physical demands in elite team handball: Comparisons between male and female players. Journal of Sports Medicine and Physical Fitness, 55(9), 878-891.

Ohnjec, K., Vuleta, D., Milanović, D., \& Gruić, I. (2008). Performance indicators of teams at the 2003 World Handball Championship for women in Croatia. Kinesiology, 4O(1), 69-79. https://hrcak.srce.hr/24835

Pereira, L. A., Nimphius, S., Kobal, R., Kitamura, K., Turisco, L. A. L., Orsi, R. C., Cal Abad, C. C., \& Loturco, I. (2018). Relationship between change of direction, speed, and power in male and female national Olympic team handbal athletes. Journal of Strength and Conditioning Research, 32(10), 2987-2994. https://doi.org/10.1519/JSC.0000000000002494

Peterson, R. A., \& Kim, Y. (2013). On the relationship between coefficient alpha and composite reliability. Journal of Applied Psychology, 98(1), 194-198. https://doi.org/10.1037/a0030767

Pollard, R., \& Gómez, M. A. (2012). Re-assessment of home advantage in Spanish handball: Comment on Gutiérrez, et al. (2012). Perceptual and Motor Skills, 115(3), 937-943. https://doi.org/10.2466/06.05.PMS.115.6.937-943

Póvoas, S. C. A., Seabra, A. F. T., Ascensão, A. A. M. R., Magalhães, J., Soares, J. M. C. \& Rebelo, A. N. C. (2012). Physical and physiological demands of elite team handball. Journal of Strength and Conditioning Research, 26(12), 3365-3375. https://doi.org/10.1519/JSC.0b013e318248aeee
Prieto, J., Gómez, M.-A., \& Sampaio, J. (2015). From a static to a dynamic perspective in handball match analysis: A systematic review. Open Sports Sciences Journal, 8, 25-34. https://doi.org/10.2174/1875399X01508010025

Saavedra, J. M. (2018). Handball research: State of the art. Journal of Human Kinetics, 63(1), 5-8. https://doi.org/10.2478/hukin-2018-0001

Saavedra, J. M., Halldórsson, K., Kristjánsdóttir, H., Porgeirsson, S., \& Sveinsson, G. (2019). Anthropometric characteristics, physical fitness and the predic tion of throwing velocity in handball men young players. Kinesiology, 51(2), 253-260. https://doi.org/10.26582/k.51.2.14

Saavedra, J. M., porgeirsson, S., Chang, M., Kristiánsdóttir, H., \& García-Hermoso, A. (2018). Discriminatory power of women's handball game-related statistics at the Olympic Games (2004-2016). Journal of Human Kinetics, 62(1), 221229. https://doi.org/10.1515/hukin-2017-0172

Saavedra, J. M., Porgeirsson, S., Kristjánsdóttir, H., Chang, M., \& Halldórsson, K. (2018). Handball game-related statistics in men at Olympic Games (20042016): Differences and discriminatory power. Retos, 32, 260-263.

Skarbalius, A., Pukėnas, K., \& Vidūnaitè, G. (2013). Sport performance profile in men's European modern handball: Discriminant analysis between winners and losers. Baltic Journal of Sport and Health Sciences, 3(90), 44-54. https://doi. org/10.33607/bjshs.v3i90.168

Valentin, L. F. (2018). Longitudinal study on the effectiveness of the game action in men's handball top competitions (1998-2016). Kinesiologia Slovenica, 24(2), 36-43. https://www.kinsi.si/en/archive/2018/319/longitudinalna-studija-o-ucinkovitosti akcij-v-igri-na-vrhunskih-tekmovanjih-moskega-rokometa-1998\%E2\%80\%932016

van den Tillaar, R., \& Ettema, G. (2004). Effect of body size and gender in overarm throwing performance. European Journal of Applied Physiology, 91(4), 413-418. https://doi.org/10.1007/s00421-003-1019-8

Vila, H., \& Ferragut, C. (2019). Throwing speed in team handball: A systematic review. International Journal of Performance Analysis in Sport, 19(5), 724-736. https://doi.org/10.1080/24748668.2019.1649344

Wagner, H., Finkenzeller, T., Würth, S., \& von Duvillard, S. P. (2014). Individual and team performance in team-handball: A review. Journal of Sports Science \& Medicine, 13(4), 808-816. https://www.jssm.org/issm-14-811.xml\%3EFulltext

Wright, C., Atkins, S., Jones, B., \& Todd, J. (2013). The role of performance analysts within the coaching process: Performance Analysts Survey 'The role of performance analysts in elite football club settings'. International Journal of Performance Analysis in Sport, 13(1), 240-261. https://doi.org/10.1080/2474866 8.2013.11868645

Yamada, E., Aida, H., \& Nakagawa, A. (2011). Notational analysis of shooting play in the middle area by world-class player and Japanese elite players in woman's handball. International Journal of Sport and Health Science, 9, 15-25. https:// doi.org/10.5432/ijshs.20100028 